\title{
MODELLING STUDIES ON SURFACE ROUGHNESS OF LAMINATED GLASS CUT BY ABRASIVE WATER JET
}

\author{
Hemavathy S, T Anil Kumar, Bijayalakshmi Das \\ Ramaiah Institute of Technology, Bangalore, India \\ Aradhya S M* \\ Kalpataru Institute of Technology, Tiptur, India \\ *Corresponding Author sma.aradhya@gmail.com
}

\begin{abstract}
Abrasive waterjet (AWJ) is a non-traditional machining process used for cutting ductile, brittle and hard materials. AWJ cuts almost all materials, absence of thermal distortion, high flexibility, smaller cutting forces, no heat affected zone and being environmentally friendly. In the present study an attempt has been made to study Depth of Cut (DOC) and Surface Roughness of laminated glass cut by AWJ. Jet Pressure (p), Speed of Traverse (u) and Flow rate of abrasive $(\dot{m})$ are varied at three different levels. A total of 27 experiments considering different levels of parameters have been carried out on a trapezoidal shaped laminated glass of $38 \mathrm{~mm}$ thickness. DOC is measured with height measuring gauge. The effect of parameters on surface roughness and DOC is obtained through main effect plot. Surface Roughness (Ra) values are measured at the wear region along cut direction. Dimensional analysis modelling for Ra is carried out to predict the model equation for Ra by Buckingham's $\pi$-method. Comparison of model average Ra and experimental average Ra is carried out to predict the suitability of the model.
\end{abstract}

Keywords: Abrasive Waterjet (AWJ), Statistical Modelling, Mathematical modeling.

Cite this Article: Hemavathy S, T Anil Kumar, Bijayalakshmi Das, Aradhya S M, Modelling Studies on Surface Roughness of Laminated Glass Cut by Abrasive Water Jet. International Journal of Mechanical Engineering and Technology 11(1), 2020, pp. $1-8$.

https://iaeme.com/Home/issue/IJMET?Volume=11\&Issue $=1$

\section{INTRODUCTION}

Abrasive Water Jet (AWJ) cutting is one of the un conventional machining processes employed in industry. In this process, high velocity of water and abrasive particles are employed to for material removal. A stream of abrasive particles are introduced into the stream of water and is made to impinge on to the work material with a high velocity. AWJ is mainly used to cut materials such as ceramics, metals, wood, marbles, and layered composites 
[1][3][4]. Surface roughness is an important parameter that ensures the quality of machined part. Quality of product has a direct relation with the surface roughness. Many literatures highlights the machining performance in AWJM for materials like tiles, marbles, glass, aluminum, etc. Cutting of laminated glass by traditional machining is difficult due to reasons such as delamination, surface damage and poor finish. It may also require secondary operations like trimming and drilling. It is found an unsafe practice in cutting both sides separately. During conventional cutting it is difficult to cut this laminated glass because it results in delamination or breakage. Also surface finish is not so good, sharp edges are formed at the cutting surface. Hence AWJ cutting of laminated glass is studied in the present work.

Ushasta Aich et al. [1] has carried out an investigation on borosilicate glass cut by AWJ machining. In this investigation depth of cut [DOC] is measured for varying cutting parameters such as standoff distance, traverse speed, abrasive flow rate, and water pressure. The results so obtained are in-line with experimental results. Kumar Abhishek et al. [2] employed grey relational analysis for optimizing the process parameters to machine holes on soda lime glass and the result of confirmation test was found to be better. UshastaAich et al. [3] has conducted experiment on cutting of borosilicate glass by AWJ machining. Material removal rate (MRR) and DOC are measured with different settings of parameters-water pressure, abrasive flow rate, traverse speed and standoff distance. Regression model of DOC has been developed and the validation result of the estimated model favors the practical use of the model in the chosen range. Dr. M. Chithirai Pon Selvan [4] carried out an investigation on surface roughness which is an important cutting performance measure in AWJ cutting of borosilicate glass. Taguchi's design of experiments was carried out in order to collect surface roughness values. Experiments were conducted by varying the traverse speed, abrasive flow rate, standoff distance and water pressure for cutting borosilicate glass using abrasive water jet cutting process. This experimental study has resulted in increased surface smoothness with reduced standoff distance. Deepak Doreswamy et. al. [5] has reported the effect of AWJ machining parameters on kerf width, on graphite filled glass fiber reinforced epoxy composite. Experiments were conducted based on Taguchi's L27 orthogonal arrays. The regression models were developed to predict kerf width. Scanning electron microscope is used to study the Surface morphology. Optimized Process parameters ensures small kerf width. R.Prabhu, V.Thirunavukkarasu [8] has worked on the influence of various process parameters in abrasive water jet machining while machining the Bullet proof glass. Surface roughness is measured with different process parameter. Waterjet pressure, abrasive flow rate, standoff distance and traverse speed are improved together by using Taguchi Grey Relational Analysis. M. Chithirai Pon Selvan and Dr. N. Mohana Sundara Raju [9] reported the influence of process parameters on surface roughness $(\mathrm{Ra})$ of cast iron. Taguchi's design of experiments was used and experiments were carried out by varying waterjet pressure, traverse speed, abrasive mass flow rate and standoff distance. It was found that surface roughness reduces as standoff distance decreases. Derzija Begic-Hajdarevic et al. [10] studied the surface roughness in AWJ cutting of Aluminium workpiece. Surface roughness was measured by using Mitutoyo stylus instrument across the depth of cut. There was a marginal change in the surface roughness upon increasing the abrasive mass flow rate. R.Horváth et.al. [11] carried out research on examination of average surface roughness in waterjet cutting and factorial design of experiments were used for further optimization. The surface roughness value is measured at different places. It was found thickness of the material is very important factor that affects the surface roughness. The Empirical model has been constructed to calculate average surface roughness $(\mathrm{Ra})$ and was found to be in good relation with the experimental results. Vlatko Marušić et.al [12] studied the effects of machining parameters on jet lagging in AWJ cutting. 


\section{EXPERIMENTATION}

\subsection{Material}

In the present investigation Laminated glass of size $300 \times 300 \times 38 \mathrm{~mm}$ (as show in figure 1) is used as specimen. The laminated glass is cut to trapezoidal shape at an angle of $45^{\circ}$. The AWJ machine is used for cutting of laminated glass is as shown in Figure 2. The machine is equipped to operate in the range between the pressure values of 1000 bar and $4500 \mathrm{Bar}$ and maximum traverse speed of $8000 \mathrm{~mm} / \mathrm{min}$ with drive motor power of $45 \mathrm{KW}$.

In the present investigation waterjet pressure $(\mathrm{MPa})$, abrasive flow rate $(\mathrm{kg} / \mathrm{min})$ and traverse speed $(\mathrm{mm} / \mathrm{min})$ are considered as control parameters. Garnet of \#80 mesh size is used for AWJ cutting. Depth of cut (DOC) and surface roughness $\left(\mathrm{R}_{\mathrm{a}}\right)$ are measured.

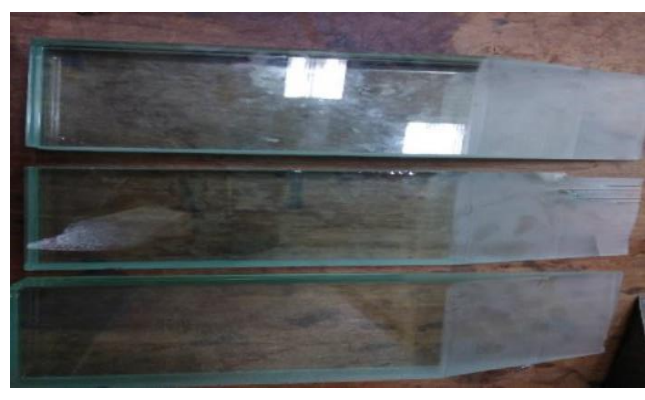

Figure 1: Laminated glass specimen

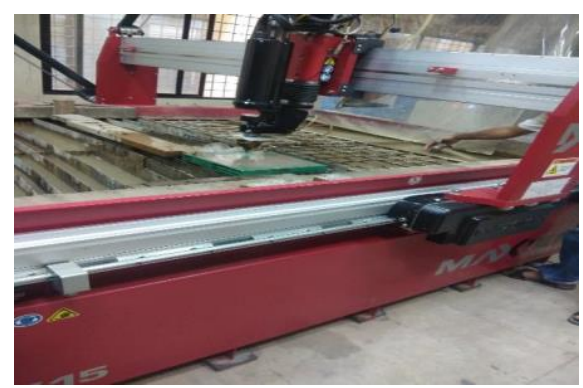

Figure 2: Abrasive Water Jet Machine

Initially cutting parameters were determined by literature review and then preliminary experiments are done, and finally cutting parameters are adjusted in an attempt to get the desired response. Water pressure p (Mpa), Traverse speed $u(\mathrm{~m} / \mathrm{min})$ \& Mass flow rate $\dot{\mathrm{m}}$ ( $\mathrm{g} / \mathrm{min})$ were selected as input parameters in the present study and three-level design is employed for modelling. By the preliminary experiment conducted using the above parameters glass was found to exhibit abrupt behavior of breaking in $300 \mathrm{MPa}$ water pressure, traverse speed of $700 \mathrm{~mm} / \mathrm{min}$. and hence water pressure was limited to $200 \mathrm{MPa}$. In order to meet the above criteria L27 orthogonal array has been chosen and three levels are selected based on Taguchi method DoE. The different levels of parameters are mention in the Table 1 given below.

Table 1: Levels of parameters used in experiment

\begin{tabular}{|c|c|c|c|c|}
\hline SL NO & Parameters & Level 1 & Level 2 & Level 3 \\
\hline 1 & Water pressure $\mathrm{p}(\mathrm{Mpa})$ & 100 & 150 & 200 \\
\hline 2 & Traverse speed u (m/min) & 300 & 400 & 500 \\
\hline 3 & Mass flow rate m $(\mathrm{g} / \mathrm{min})$ & 199 & 309 & 425 \\
\hline
\end{tabular}

The cutting experiment is carried out on the laminated glass with the above stated parameter values from preliminary experimentation. The experimentation is conducted for the 27 combinations of the selected input parameters. Depth of cut (DoC) and surface roughness is measured for each trial. 


\subsection{Measurement of DOC}

The depth of cut (DOC) is measured using height measuring gauge as shown in figure 3.

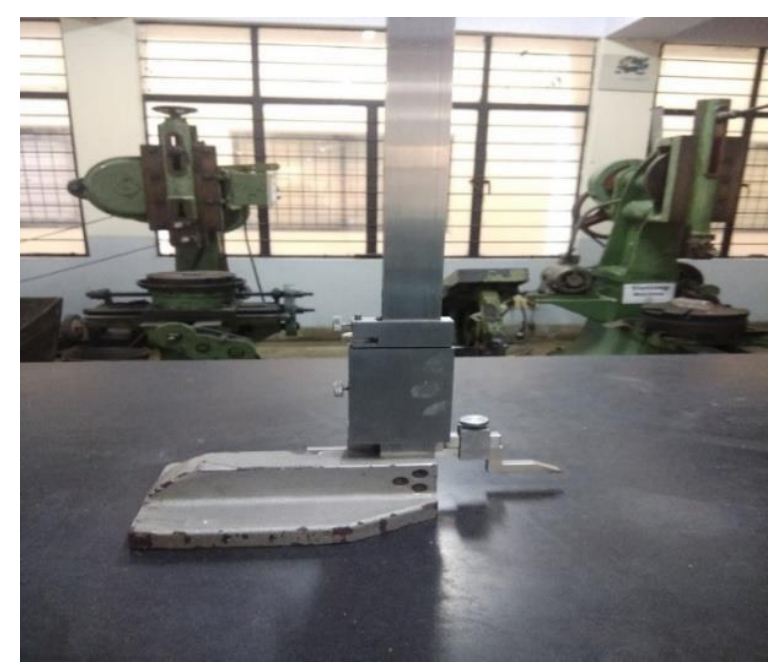

Figure 3: Height measuring gauge

\subsection{Measurement of Surface Roughness}

The $\mathrm{R}_{\mathrm{a}}$ is measured using Mitutoyo surface tester and it is measured for all the 27 experiments at cutting wear region along the DOC. The stylus material is a diamond tip of radius $5 \mu \mathrm{m}$ with sensor moving along the surface of the sample.

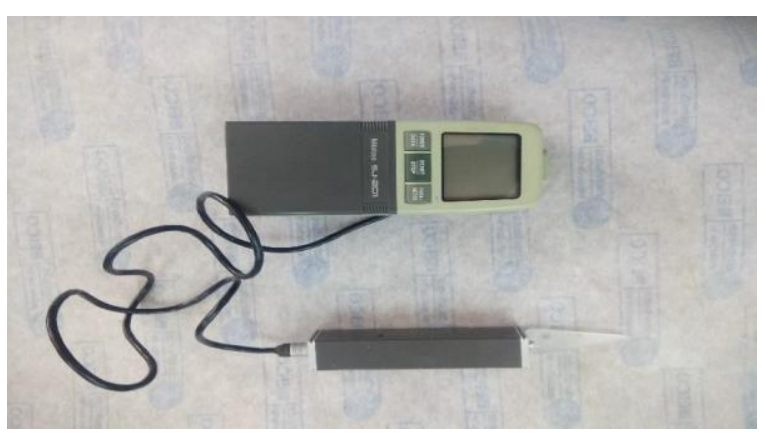

Figure 4. Mitutoyo surface roughness test instrument

\section{RESULT AND DISCUSSIONS}

The results for DOC and Ra is shown in the below table

Table 2. Experimental results of DOC and Ra

\begin{tabular}{|c|c|c|c|c|c|}
\hline EXP.NO & $\mathbf{p}[\mathbf{M P a}]$ & $\dot{\mathbf{m}}[\mathbf{k g} / \mathbf{m i n}]$ & $\mathbf{u}[\mathbf{m m} / \mathbf{m i n}]$ & $\mathbf{D O C}[\mathbf{m m}]$ & Average Ra $(\boldsymbol{\mu m})$ \\
\hline 1 & 100 & 0.199 & 300 & 13 & 3.565 \\
\hline 2 & 100 & 0.199 & 400 & 11.5 & 3.685 \\
\hline 3 & 100 & 0.199 & 500 & 10 & 3.67 \\
\hline 4 & 100 & 0.309 & 300 & 15 & 3.65 \\
\hline 5 & 100 & 0.309 & 400 & 11 & 3.43 \\
\hline 6 & 100 & 0.309 & 500 & 9 & 3.61 \\
\hline 7 & 100 & 0.425 & 300 & 13.5 & 3.635 \\
\hline 8 & 100 & 0.425 & 400 & 12 & 3.65 \\
\hline 9 & 100 & 0.425 & 500 & 11 & 3.87 \\
\hline 10 & 150 & 0.199 & 300 & 22.5 & 4.10 \\
\hline 11 & 150 & 0.199 & 400 & 18 & 3.816 \\
\hline
\end{tabular}




\begin{tabular}{|c|c|c|c|c|c|}
\hline EXP.NO & $\mathbf{p}[\mathbf{M P a}]$ & $\dot{\mathbf{m}}[\mathbf{k g} / \mathbf{m i n}]$ & $\mathbf{u}[\mathbf{m m} / \mathbf{m i n}]$ & $\mathbf{D O C}[\mathbf{m m}]$ & Average Ra $(\boldsymbol{\mu m})$ \\
\hline 12 & 150 & 0.199 & 500 & 17 & 4.06 \\
\hline 13 & 150 & 0.309 & 300 & 21 & 4.19 \\
\hline 14 & 150 & 0.309 & 400 & 18 & 4.08 \\
\hline 15 & 150 & 0.309 & 500 & 15 & 3.62 \\
\hline 16 & 150 & 0.425 & 300 & 19 & 4.036 \\
\hline 17 & 150 & 0.425 & 400 & 18 & 3.656 \\
\hline 18 & 150 & 0.425 & 500 & 16.5 & 3.823 \\
\hline 19 & 200 & 0.199 & 300 & 24.5 & 3.856 \\
\hline 20 & 200 & 0.199 & 400 & 23.5 & 4.204 \\
\hline 21 & 200 & 0.199 & 500 & 22 & 4.21 \\
\hline 22 & 200 & 0.309 & 300 & 28 & 3.596 \\
\hline 23 & 200 & 0.309 & 400 & 24.5 & 3.903 \\
\hline 24 & 200 & 0.309 & 500 & 23 & 4.023 \\
\hline 25 & 200 & 0.425 & 300 & 28.5 & 4.25 \\
\hline 26 & 200 & 0.425 & 400 & 24 & 3.996 \\
\hline 27 & 200 & 0.425 & 500 & 22.5 & 4.218 \\
\hline
\end{tabular}

The maximum DOC is obtained for highest water pressure of $200 \mathrm{MPa}$ and highest abrasive mass flow rate of $0.425 \mathrm{~kg} / \mathrm{min}$ with lowest traverse speed of $300 \mathrm{~mm} / \mathrm{min}$ cutting condition. At higher water pressure, more amount of kinetic energy is available with the water. This high pressure water coupled with high abrasive flow rate will provide more water jet energy and more number of cutting edges of abrasive particles for cutting of glass. In addition, lesser traverse speed of water jet will assist this high pressure water with more number of abrasive particles to cut at a point for more duration of time when compared to lesser traverse speed jet. The above reasons will help in achieving higher DOC.

Similarly, minimum DOC is achieved for lower water jet pressure of $100 \mathrm{MPa}$ with abrasive mass flow rate of $0.199 \mathrm{~kg} / \mathrm{min}$ and higher traverse speed of $500 \mathrm{~mm} / \mathrm{min}$ cutting condition. At lower water jet pressure less amount of energy is available for cutting of glass. This low pressure of water is coupled with low abrasive flow rate thus providing less water jet energy followed by reduction in number of cutting edges of abrasive particles for cutting of glass. In addition, higher traverse speed of water jet will assist low pressure water with less abrasive particles to cut at a point for less duration of time. Hence this is the reason for lower DOC.

Surface roughness is measured along the DOC for all 27 experimental specimens on the cutting wear zone only due to the limitations on use of Mitutoyo surface tester. The measurements are conducted from the top surface to one-third the distance from top surface of the cut. This region is considered to be cutting wear region. Table 2 shows the average $R_{a}$ for all 27 experimental conditions.

\subsection{Main effect plots for Depth of cut}

The main effect plot is used to find the influence of the process parameters. Figure 6 shows the influence of process parameters on DOC of laminated glass cut by AWJ cutting process using Minitab software package. The best combination of input parameters to optimize DOC can be easily found from this plot. From Figure 5, it has seen that the water pressure and traverse speed slope is more, hence these two parameters has greater influence on the DOC. 


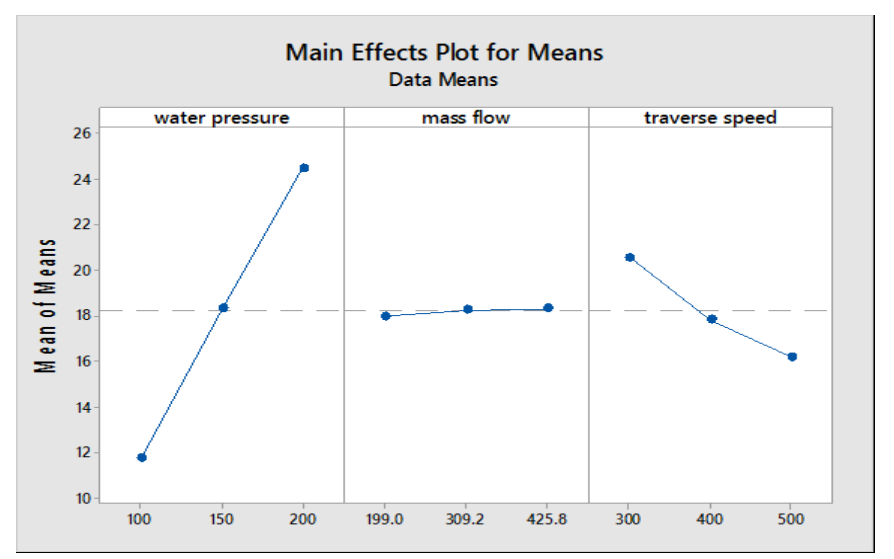

Figure 5. Main effect plot of process parameters on DOC

\subsection{Mathematical Modeling of $\mathbf{R}_{\mathbf{a}}$}

In the present study Buckingham's $\pi$-method is used to determine the relationship between $\mathrm{R}_{\mathrm{a}}$ and Water pressure $(\mathrm{p})$, abrasive mass flow rate $(\dot{\mathrm{m}}) \&$ Traverse speed $(\mathrm{u})$ :

$R_{a}=f(p m \dot{U})$

$\pi_{1}=p^{a} m^{b} \dot{u}^{c} R_{a}$

Solving, $a=\frac{1}{2}, b=-\frac{1}{2} \& c=-\frac{1}{2}$

So, $\pi_{1}=p^{\frac{1}{2}} \dot{m}^{-\frac{1}{2}} u^{-\frac{1}{2}} R_{a}$

$\pi 1=R_{a} \sqrt{\frac{p}{m u}}$

Using power law

$R_{a}=b\left(\frac{m u}{p}\right)^{1 * \frac{a}{2}}$

Where $\mathrm{a} \& \mathrm{~b}$ are constants to be evaluated from experimental data

On solving,

$a=-0.13 \& b=6.05$

Finally, the model equation for $\mathrm{R}_{\mathrm{a}}$ is

$R_{a}=6.05\left(\frac{m \cdot u}{p}\right)^{-0.067}$

So this is the model equation to find average $\mathrm{R}_{\mathrm{a}}$ on cutting wear region.

Percentage of error $=\frac{\text { modelR }_{\boldsymbol{a}}-\text { Average experimental } \mathbf{R}_{\boldsymbol{a}}}{\operatorname{model} \mathbf{R}_{\boldsymbol{a}}}$

The graph below shows the experimental surface roughness and the surface roughness values obtained using mathematical modeling: 


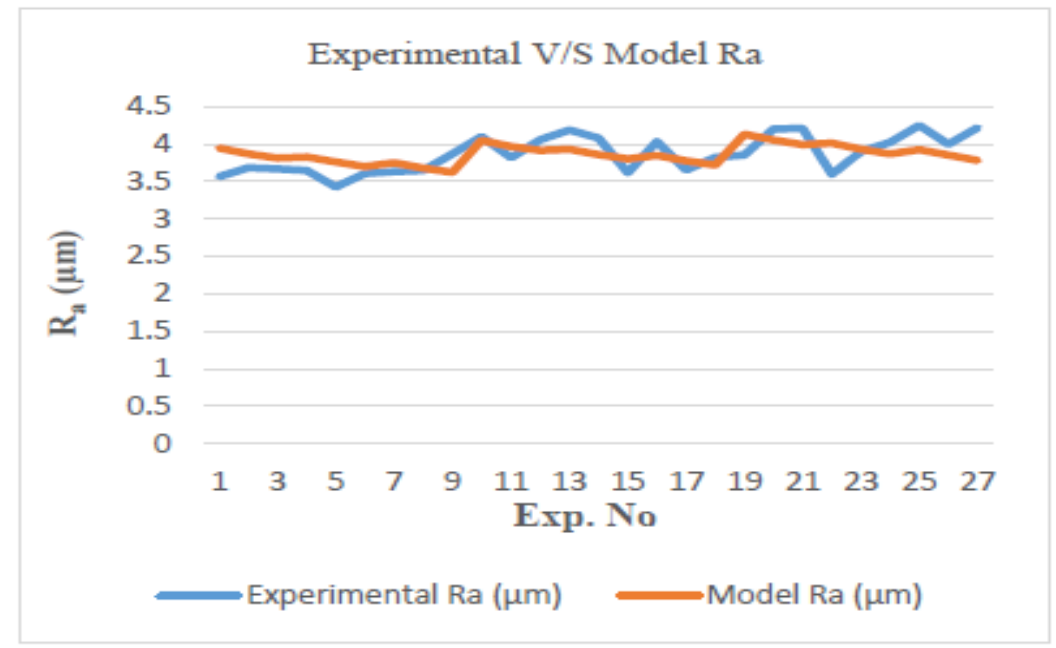

Figure 6

The minimum model $\mathrm{R}_{\mathrm{a}}$ valve is $3.62 \mu \mathrm{m}$ obtained for cutting condition $100 \mathrm{MPa}$ waterjet pressure, $0.425 \mathrm{~kg} / \mathrm{min}$ of abrasive flow rate and $500 \mathrm{~mm} / \mathrm{min}$ of traverse speed. The maximum $\mathrm{R}_{\mathrm{a}}$ valve is $4.133 \mu \mathrm{m}$ obtained for the cutting conditions of $200 \mathrm{MPa}$ waterjet pressure, $0.199 \mathrm{~kg} / \mathrm{min}$ abrasive flow rate and $300 \mathrm{~mm} / \mathrm{min}$ traverse speed. The $R_{a}$ valves obtained from modelling are compared with average experimental $R_{a}$ and the error in terms of percentage is calculated. Then comparison of model $R_{a}$ and average experimental $R_{a}$ were made, the proposed model predicted almost $\pm 10 \% \mathrm{R}_{\mathrm{a}}$ value than the experimental values.

\section{CONCLUSION}

In the present work, analysis of DOC and model equation for surface roughness $\mathrm{R}_{\mathrm{a}}$ for laminated glass cut by AWJ is developed. The experiments were done on the $38 \mathrm{~mm}$ thickness of trapezoidal shaped laminated glass. Water pressure is the main reason for higher DOC compared to abrasive flow rate and traverse speed. The lowest average $\mathrm{R}_{\mathrm{a}}$ value for the cutting wear region is $3.43(\mu \mathrm{m})$ is obtained for cutting condition of Waterjet pressure $\mathrm{p} 100$ $\mathrm{MPa}$, abrasive flow rate $\dot{\mathrm{m}} 0.309 \mathrm{~kg} / \mathrm{min} \&$ traverse speed u $400 \mathrm{~mm} / \mathrm{min}$. For better $\mathrm{R}_{\mathrm{a}}$ values higher waterjet pressure (p), higher Mass flow rate $\dot{\mathrm{m}}$ and lower traverse speeds are recommended. Similarly for Waterjet pressure $\mathrm{p}$ of $200 \mathrm{MPa}$, abrasive flow rate $\dot{\mathrm{m}}$ of $0.425 \mathrm{~kg} / \mathrm{min} \&$ traverse speed $\mathrm{u}$ of $500 \mathrm{~mm} / \mathrm{min}$ has the highest average $\mathrm{R}_{\mathrm{a}}$ value for the cutting wear region is $4.218(\mu \mathrm{m})$.

\section{REFERENCES}

[1] Ushasta Aicha, Simul Banerjeea, Asish Bandyopadhyaya, Probal Kumar Das Abrasive Water Jet Cutting of Borosilicate Glass, (2014) 775 - 785

[2] Kumar Abhishek, Somashekhar S Hiremath, Machining of Micro-holes on Sodalime Glass using Developed Micro- Abrasive Jet Machine ( $\mu$-AJM), (2016) 1234 - 1241

[3] Dr. M. Chithirai Pon Selvan, Jerrin Varghese, Effects of Process Parameters on Surface Roughness in Abrasive Water jet Cutting of Borosilicate Glass, (2016) Vol 1

[4] UshastaAich1, Simul Banerjee, AsishBandyopadhyay, Probal Kumar Das, Simultaneous modeling of responses in AWJM of Borosilicate glass by SVM and SEM study, (2014), 130-1 - 130-6

[5] Deepak Doreswamy, Basavanna Shivamurthy, Devineni Anjaiah, and N. Yagnesh Sharma An Investigation of Abrasive Water Jet Machining on Graphite/Glass/Epoxy Composite Volume 2015, Article ID 627218, 11 pages 
[6] Victor Wessels,Anton Grigoryev \& Eduardo Weingärtner, Abrasive waterjet machining of three-dimensional structures from bulk metallic glasses and comparison with other techniques, (2012) 1187- 1191

[7] The Mechanical Properties of Glass Theoretical strength, practical strength, fatigue, flaws, toughness, chemical processes Glass Engineering 150:312 Professor Richard Lehman Department of Ceramics and Materials Engineering Rutgers University, New Brunswick, New Jersey, USA

[8] Optimization of machining parameters for machining bullet proff glass using awjm R.Prabhu, V.Thirunavukkarasu, M.Ramasubramanian

[9] M. Chithirai Pon Selvan and Dr. N. Mohana Sundara Raju analysis of surface roughness in abrasive waterjet cutting of cast iron (2012) $174-182$

[10] P. Badgujar M. G. Rathi Analysis of Surface Roughness in Abrasive Waterjet Cutting Of Stainless Steel Vol. 3 Issue 6, June - 2014

[11] Peter Miles, Axel Henning a better measurement of abrasive waterjet cut surface finishes September 9-11, 2013

[12] Derzija Begic-Hajdarevica, Ahmet Cekica, Muhamed Mehmedovicb, Almina Djelmica Experimental Study on Surface Roughness in Abrasive Water Jet Cutting (2015 ) 394 399

[13] R. Horváth, Á. Drégelyi-Kiss, J. Lukács Examination of average surface roughness in waterjet cutting 2016

[14] Sai Shridhar Joshi, Chaitanya Shaligram :A Review Of Analysis Of Surface Roughness In Abrasive Water Jet Cutting 2017 Volume 5 